\title{
Intradural Extramedullary Spinal Canal Neoplasm
}

National Cancer Institute

\section{Source}

National Cancer Institute. Intradural Extramedullary Spinal Canal Neoplasm. NCI

Thesaurus. Code C5135.

A neoplasm that occurs within the spinal canal in the space between the spinal cord and the dura mater. Representative examples include meningioma, neurofibroma, and sarcoma. Signs and symptoms include local and radicular pain, weakness and spinal cord compression. 